\title{
KONSTRUKSI SOSIAL ISLAM MODERAT JAMAAH MAIYAH MOCOPAT SYAFAAT PADA GENERASI MILENIAL DI YOGYAKARTA
}

\author{
Khotim Hanifudin Najib ${ }^{1 *}$, Achmad Habibullah ${ }^{2}$ \\ ${ }^{1}$ Universitas Sarjanawiyata Tamansiswa Yogyakarta, INDONESIA \\ ${ }^{2}$ Puslitbang Pendidikan Agama dan Keagamaan, Badan Litbang dan Diklat, INDONESIA \\ *Correspondence: 《hotim.najib@ustjogja.ac.id
}

\begin{abstract}
Understanding moderate Islam is very important to millennial Muslim generations in Indonesia. Today, this millennial generation is threatened by exposure to radicalism and intolerance, such as environmental studies, reading books and the Internet. This paper is a phenomenological study of the recitation of the congregation of intercessors Maiyah mocopat to inculcate moderate Islamic understanding in the millennial generation in Yogyakarta. The externalization of moderate Islam towards the millennial generation is achieved by creating a comfortable and enjoyable learning environment. Activities that occurred during this interfaith prayer session included Al-Quran, Shalawat, Group Discussions, delivery of resource materials, sharing, and events interspersed with Kyai Kanjeng music performances. The activity makes the millennial generation have an objective understanding (objectivation) about peaceful Islam, soothing Islam, and moderate Islam. The internalization of moderate Islam is carried through primary socialization and secondary socialization. Primary socialization is carried in the family environment with the exemplary method. Whereas secondary socialization is carried in educational institutions such as schools, recitals, including through interfaith recitation sessions which held every 17th of the month
\end{abstract}

\begin{abstract}
Abstrak
Paham Islam moderat sangat penting bagi generasi muslim Milenial Indonesia. Namun saat ini generasi milenial ini terancam terpapar paham Radikal dan intoleran, terutama dari kajian-kajian lingkungan sekitar, buku-buku bacaan dan Internet. Artikel ini merupakan kajian fenomenologi tentang pengajian jamaah maiyah mocopat syafaat dalam menanamkan paham Islam moderat kepada generasi Milenial di Yogyakarta. Tulisan ini memperlihatkan bahwa konstruksi sosial Islam Moderat Jamaah Maiyah Mocopat syafaat terhadap generasi milenial dilakukan pada tiga proses, yaitu Eksternalisasi, Objektivasi dan Internalisasi. Eksternalisasi Islam moderat terhadap generasi milenial dilakukan dengan menciptakan lingkungan pengajian yang nyaman dan menyenangkan. Kegiatan yang berlangsung selama pengajian mocopat syafaat ini di antaranya tadarus Al-Quran, Shalawat, Diskusi kelompok, penyampaian materi dari Narasumber, sharing, dan acara diselingi penampilan musik Kyai kanjeng. Kegiatan tersebut membuat generasi milenial memiliki pemahaman obyektif (objektivasi) tentang Islam yang damai, Islam yang menyejukkan dan Islam moderat. Internalisasi Islam moderat dilakukan melalui sosialisasi primer dan sosialisasi sekunder. Sosialisasi primer dilakukan pada lingkungan keluarga dengan metode keteladanan. Sedangkan sosialisasi sekunder dilakukan di lembaga-lembaga pendidikan seperti sekolah, pengajian, termasuk melalui pengajian Mocopat Syafaat yang diadakan setiap tanggal 17 di setiap bulannya
\end{abstract}

Article History

Received: $24-10-2020$,

Revised: 13-12-2020,

Accepted: $31-12-2020$

\section{Keywords:}

The externalization of moderate Islam,

The intercession of Maya

Mocopat;

The millennial generation;

The moderate Islamic social constructs;

Histori Artikel

Diterima: 24-10-2020

Direvisi: 13-12-2020

Disetujui: 31-12-2020

Kata Kunci:

Eksternalisasi Islam

moderat;

Generasi Milenial;

Konstruksi Sosial Islam

Moderat;

Maiyah Mocopat Syafaat;

(C) 2020 Khotim Hanifudin Najib, Achmad Habibullah

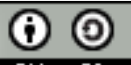

EY SA This work is licensed under a Creative Commons Attribution-ShareAlike 4.0 International License.

\section{A. Pendahuluan}

Jamaah Maiyah mocopat syafaat (MMS) memegang peranan penting dalam pemeliharaan kesatuan dan persatuan bangsa Indonesia. Maiyah Mocopat Syafaat merupakan sebuah forum 
KONSTRUKSI SOSIAL ISLAM ...

diskusi (sinau bareng) yang sangat sederhana, namun semua ilmu dielaborasikan, tidak ada jarak yang begitu jauh antara audiens dengan narasumber. Forum ini sudah berlangsung cukup lama, telah melalui proses dan perjalanan panjang. Bukan hal yang mudah tentunya menjaga sebuah kontinuitas berjalannya forum diskusi yang sangat cair ini. Begitu cairnya Maiyah Mocopat Syafaat, bahkan ia disebut sebagai sebuah laboratorium ilmu bersama (Ma`a) ${ }^{1}$. Forum ini mampu memikat para generasi milenial untuk ikut serta di dalam berdiskusi aktif di dalamnya. Sehingga melalui forum ini pula, ideologi dan pemikiran para generasi milenial itu dibangun.

Forum diskusi MMS berisikan kegiatan-kegiatan seperti lantunan sholawat, wirid dan doa serta diselingi musik dan kesenian untuk menumbuhkan semangat spiritualitas dan kebudayaan, sembari diajak diskusi berfikir tentang realitas kehidupan dan cara menyikapi kehidupan itu sendiri. ${ }^{2}$ Kegiatan kajian dalam forum MMS ini lebih bersifat diskusi atau sharing tentang topiktopik kemanusiaan, mengajarkan semangat hidup, sikap toleran dan hidup bersama dalam kontribusi kebaikan. Kemudian anggota dari kegiatan ini dinamakan sebagai Jamaah maiyah, dimana keanggotaannya tidak bersifat mengikat dan tidak identik sebagai sekumpulan orang Islam saja. Setiap orang bebas datang dan mengikuti kajian tersebut. ${ }^{3}$ Forum kajian seperti inilah yang sejatinya dibutuhkan bagi bangsa Indonesia, sebagai upaya untuk menanamkan sikap moderat dalam diri generasi milenial.

Kajian-kajian ilmiah telah banyak memaparkan tentang karakter masyarakat Indonesia yang majemuk dan sangat membutuhkan paham Islam moderat, bukan radikal. Mereka sepakat bahwa paham radikal ini mengancam eksistensi bangsa Indonesia ${ }^{4}$. Dikatakan mengancam karena bertentangan dengan konteks dan karakter bangsa Indonesia yang majemuk. Islam Indonesia haruslah Islam moderat, Islam yang ramah dan Islam yang damai. Zuhairi Misrawi menjelaskan paradigma moderat dengan merujuk buku yang ditulis oleh ahli hukum Islam, yaitu Dr. Nadirsyah Hosen yang berjudul Sharia and Constitutional Reform in Indonesia bahwa Islam harus dipahami sebagai nilai, kebijakan, kemaslahatan bersama (common good) dan tatanan moral. Sistem Islam dalam ruang publik bertujuan untuk menegakkan kesetaraan diantara warga negara. Nilai-nilai Islam yang Universal dijadikan sebagai Common ground atau common platform dengan agamaagama lainnya. Sehingga istilah yang dipilih oleh bangsa Indonesia yang tertuang pada Pancasila adalah Ketuhanan Yang Maha Esa ${ }^{5}$.

Radikalisme dan intoleransi masih mengancam bangsa Indonesia. Paham ini dapat disemai dan terus tumbuh di sepanjang musim dan ladang persawahan yang lain, yakni kelompok-kelompok pengajian. Abdul Munip dalam tulisannya menjelaskan bahwa paham radikal telah mulai masuk ke dalam pemikiran-pemikiran para remaja milenial di Indonesia ${ }^{6}$. Baik pada jenjang pendidikan menengah hingga pendidikan tinggi. Kalangan generasi milenial sangat rentan untuk dipenetrasi

${ }^{1}$ Muhammad Azizul Mustafa, "Maiyah mocopat syafaat dalam perspektif psikologi," LENTERA 1, no. 01 (June 18, 2017), hlm: 26, https://doi.org/10.21093/lentera.v1i01.839.

${ }^{2}$ Saputra Prayogi R., Spiritual Journey: Pemikiran Dan Perenungan Emha Ainun Nadjib (Jakarta: KOMPAS, 2012), hlm: 88 .

${ }^{3}$ Mustafa, "Maiyah mocopat syafaat dalam perspektif psikologi,", hlm: 21.

${ }^{4}$ Ahmad Rizky Mardhatillah Umar, "Melacak Akar Radikalisme Islam Di Indonesia," Jurnal Ilmu Sosial Dan Ilmu Politik 14, no. 2 (November 1, 2010), hlm: 169-86, https://doi.org/10.22146/jsp.10935.

5 Zuhairi Misrawi, Pandangan Muslim Moderat: Toleransi, Terorisme Dan Oase Perdamaian (Jakarta: KOMPAS, 2010).

${ }^{6}$ Abdul Munip, "Menangkal Radikalisme Agama Di Sekolah,” Jurnal Pendidikan Islam 1, no. 2 (December 25, 2012), hlm: 159-81, https://doi.org/10.14421/jpi.2012.12.159-181. 
KONSTRUKSI SOSIAL ISLAM ...

semangat dan pemahaman radikalisme keagamaan ${ }^{7}$. Apa lagi saat ini dukungan moral orang tua sudah hilang akibat dari urbanisasi. Keluarga milenial saat ini terjebak pada ritme kerja yang cepat, volume padat, dengan batas waktu yang tepat. Akibatnya kehangatan keluarga terceraikan dari para generasi milenial. Hal ini mengakibatkan mereka lebih asyik dengan dunia privatnya. Sebagai respons, para aktivis Islam dengan berbagai latar belakang aliran keislaman mendirikan kelompokkelompok pengajian dan menggelar mimbar-mimbar publik yang bersifat baik di masjid, majelis taklim, maupun kampus-kampus. Bahkan ada yang sampai menawarkan program keislaman dari pintu ke pintu rumah atau perkantoran ke perkantoran. Hal ini juga dimanfaatkan oleh merakan para aktivis Islam radikal/intoleran dengan mendirikan kelompok-kelompok kecil atau memasuki kelompok-kelompok yang telah ada baik di lembaga pendidikan formal maupun di luar lembaga ${ }^{8}$. Temuan yang sangat menarik muncul dari hasil survei yang dilakukan Wahid Foundation dan kementerian Agama RI terhadap aktivis Rohis di SMA/SMK Negeri di Indonesia pada Mei 2016. Hasil survei tersebut menggambarkan bahwa $60 \%$ responden bersedia berjihad ke wilayah-wilayah konflik jika ada kesempatan. 68\% responden bersedia melakukan jihad di masa mendatang. Dan 6\% mendukung ISIS. Laporan ini menggambarkan bahwa Generasi milenial rentan terpapar radikalisme dan intoleransi terutama melalui kajian-kajian atau lembaga-lembaga formal.

Forum-forum kajian di Yogyakarta sebenarnya tidak hanya MMS saja, melainkan masih banyak forum-forum pengajian lain yang tersedia di kota ini. Namun, forum kajian yang memiliki karakteristik seperti MMS ini tidak banyak. Forum kajian ini sangat unik. Letak keunikan Maiyah Mocopat Syafaat ini salah satunya adalah terjaganya semangat kesadaran bersama bahwa semua orang yang hadir berhak untuk berbicara. Semua yang hadir berhak untuk mengemukakan kebenaran menurut versinya masing-masing dan tidak ada paksaan untuk menyetujui atas pendapat yang dikemukakan. Semua orang memiliki kebebasan yang sama untuk menentukan setuju atau tidak setuju?

Kajian dalam forum ini tidak hanya pada bidang agama. Namun bidang keilmuan lain juga ikut di elaborasi dalam forum kajian ini. Forum kajian ini pun bisa dikaji dari berbagai bidang keilmuan. Muh. Azizul Mustofa misalnya, ia mengkaji jamaah Maiyah Mocopat Syafaat dengan sudut pandang psikologi. Dalam pandangnya, ia menempatkan sosok Emha Ainun Najib sebagai sosok psikolog dan jamaah pengajian tersebut sebagai pesertanya. Empat perspektif psikologi ia jadikan pisau analisis untuk memahami fenomena tersebut, yaitu perspektif psikoanalitik, Behaviorisme, Humanis, dan Transpersonal ${ }^{10}$. Berbeda dengan Muh. Azizul, Ahmad Sadam Husaein mengkaji forum ini dari sudut pandang Komunikasi dan Pendidikan Islam. Hasil penelitiannya menjelaskan bahwa karakter komunikasi Emha Ainun Najib dalam forum kajian tersebut memiliki 7 karakteristik komunikasi, yaitu Komunikasi kultural, komunikasi egaliter, komunikasi interaksional, komunikasi kontekstual, komunikasi dekonstuktif, komunikasi analogis dan retorika rekreatif ${ }^{11}$.

\footnotetext{
${ }^{7}$ Ramlah Hakim, "Paham dan sikap keagamaan mahasiswa muslim di kota Samarinda," Al-Qalam 16, no. 1 (August 12, 2018), hlm: 17, https://doi.org/10.31969/alq.v16i1.490.

${ }^{8}$ Huda M.N, Pemuda, Kelas Menengah Muslim, Dan Tantangan Intoleransi Dan Radikalisme Di Perkotaan (Jakarta: Wahid Foundation, 2017), hlm: 11.

${ }^{9}$ Mustafa, "Maiyah mocopat syafaat dalam perspektif psikologi,”, hlm: 26.

${ }^{10}$ Mustafa, hlm: 35.

11 Husaein Ahmad Sadam, "Karakteristik Komunikasi Emha Ainun Nadjib Dalam Penanaman Nilai-Nilai Pendidikan Islam Di Forum Maiyah Mocopat Syafaat.” (Thesis, Yogyakarta, Universitas Islam Negeri Yogyakarta, 2015).
} 
KONSTRUKSI SOSIAL ISLAM ...

Berbeda dengan dua penelitian diatas, penelitian ini menggunakan konstruksi sosial Peter L Berger sebagai pisau analisis untuk mengupas fenomena yang terjadi pada Jamaah Maiyah Mocopat Syafaat. Sosiologi pengetahuan Peter L. Berger dianggap mampu menjelaskan tentang fenomena MMS yang memiliki daya tarik bagi generasi Milenial, sehingga forum tersebut mampu membangun pemahaman Islam yang sesuai dengan konteks bangsa Indonesia. Menurut Berger, pengetahuan manusia itu di bangun oleh realitas kehidupan. Ia meyakini bahwa proses dialektika fundamental dari masyarakat terdiri dari tiga momentum yaitu eksternalisasi, objektivasi dan internalisasi. $^{12}$

Eksternalisasi adalah suatu pencurahan kedirian manusia secara terus menerus ke dalam dunia, baik dalam aktivitas fisik maupun mentalnya. Eksternalisasi merupakan suatu keharusan antropologis. Kedirian manusia bagaimanapun tidak bisa dibiarkan tetap tinggal diam di dalam dirinya sendiri, dalam suatu lingkup tertutup, dan kemudian bergerak keluar untuk mengekspresikan diri dalam dunia sekelilingnya. Proses biologis "menjadi manusia" akan dilalui oleh setiap orang. proses ini dimulai dari ia dilahirkan. Namun manusia itu "belum selesai saat dia dilahirkan"13 Objektivasi adalah disandangnya produk-produk aktivitas itu (baik fisik maupun mental), suatu realitas yang berhadapan dengan para produsennya semula, dalam bentuk suatu kefaktaan yang eksternal terhadap, dan lain dari, para produser itu sendiri. Internalisasi adalah peresapan kembali realitas tersebut oleh manusia, dan mentransformasikan sekali lagi dari struktur-struktur dunia obyektif ke dalam struktur-struktur kesadaran subjektif. melalui objektivasi, maka masyarakat menjadi suatu realitas sui generis, unik. Melalui internalisasi, maka manusia merupakan produk masyarakat. ${ }^{14}$ Internalisasi diperkuat dengan dua proses yaitu, sosialisasi primer dan sosialisasi sekunder. Sosialisasi primer adalah sosialisasi pertama yang di alami individu pada masa kanakkanak, sehingga dari proses itu anak-anak tersebut menjadi anggota masyarakat. Sedangkan sosialisasi sekunder adalah internalisasi sejumlah sub dunia, sehingga lingkup jangkauan dan sifatnya ditentukan oleh kompleksitas distribusi pengetahuan dalam masyarakat.

Artikel ini bertujuan untuk menjelaskan tentang proses konstruksi sosial yang terjadi pada forum kajian MMS. Hal ini menjadi sangat penting untuk dilakukan, karena ideologi seseorang itu akan sangat mempengaruhi sikap dan perilakunya dalam kehidupan sehari-hari. Sehingga secara tidak sadar ideologi dan pemahaman kita itu dibangun oleh lingkungan sosialnya. Oleh Peter L. Berger diterjemahkan sebagai peran institusi masyarakat dalam pengetahuan manusia. Ia menjelaskan bahwa manusia adalah produk sosial/ masyarakat. ${ }^{15}$

\section{B. Metode Penelitian}

Artikel ini merupakan penelitian lapangan (field research) dengan jenis penelitian fenomenologi. Penelitian fenomenologi ini fokus pada menggambarkan apa yang dimiliki semua peserta saat mereka mengalami fenomena ${ }^{16}$. Objek kajian dalam penelitian ini adalah kajian Maiyah Mocopat Syafaat yang secara rutin dilaksanakan setiap tanggal 17 berlokasi di Tamantirto, Kasihan, Bantul, Yogyakarta. Adapun teknik pengumpulan data yang digunakan adalah observasi dan wawancara mendalam serta dokumentasi. Selanjutnya setelah data dikumpulkan, peneliti melakukan pereduksian data, penyajian data, dan penarikan kesimpulan atas interpretasi data yang

\footnotetext{
${ }^{12}$ Peter L. Berger, Langit Suci: Agama Sebagai Realitas Sosial (Jakarta: LP3S, 1991).

13 Berger, hlm: 6.

14 Berger, hlm: 5.

15 Peter L. Berger and Thomas Luckmann, The Social Construction of Reality: A Treatise in the Sociology of Knowledge (Great Britain: Penguin Books Ltd, 1991), hlm: 79.

16 John W Creswell, Qualitative Inquiry and Research Design: Choosing among Five Approach, 2nd ed. (London: SAGE Publication, 2017), hlm: 57.
} 
KONSTRUKSI SOSIAL ISLAM ...

diperoleh dan mengaitkannya dengan teori inti dalam penelitian ini, yaitu teori konstruksi sosial yang dikemukakan oleh Peter L. Berger dan Thomas Luckmann.

\section{Pembahasan atau Analisis}

\section{Eksternalisasi Islam moderat pada jamaah Maiyah Mocopat Syafaat}

Eksternalisasi merupakan suatu proses alamiah manusia sebagai makhluk sosial. Berger menyebutkan bahwa eksternalisasi merupakan suatu keharusan antropologis. Ia adalah sebuah keniscayaan, karena manusia tidak bisa terlepas dari lingkungan kehidupannya. Manusia tidak bisa hidup sendiri. Mereka membutuhkan orang lain agar dapat menjalani kehidupan sehari-hari. Karena hal tersebutlah manusia berinteraksi dengan lingkungannya. Proses interaksi tersebut dipercaya oleh Berger dapat mempengaruhi pribadi seseorang. Bahkan merupakan awal dari sebuah pembentukan diri seorang manusia.

Pada bagian ini akan dideskripsikan tentang eksternalisasi Islam moderat jamaah maiyah mocopat syafaat terhadap generasi milenial. Eksternalisasi tentunya mengacu pada teori konstruksi sosial Peter L. Berger. Teori tersebut juga akan digunakan untuk mengupas atau menganalisis fenomena yang ditemui di lapangan.

Eksternalisasi Islam moderat pada generasi milenial diawali dengan pembentukan lingkungan sosial yang sudah dirancang sedemikian rupa untuk mampu menanamkan pemahaman Islam moderat kepada mereka. Pola pengajian Mocopat Syafaat yang dapat peneliti tangkap yaitu diantaranya sharing, penampilan musik, diskusi tematik dan narasumber yang menarik. OKT menjelaskan bahwa ia tertarik dengan pengajian ini karena "Ya kadang kan ada sharing, terus kalo itu kan ada gamelan, musik, nanti narasumbernya beda-beda terus". Lanjut ia menjelaskan bahwa "Kan kalo ikut pengajian kan ada pak ustad nya berbicara di depan, kadang tanya jawab adalah satu dua, tapi kalo di cak nun (Mocopat Syafaat), ada sedikit selingan kyai kanjeng, musiknya"17

Selain itu, Generasi milenial di Yogyakarta merasa nyaman dengan model pengajian Jamaah Mocopat Syafaat, sehingga mereka lebih memilih pengajian Mocopat Syafaat yang terletak di Kasihan Bantul ini. Mereka merasa nyaman karena dalam pengajian itu terjadi interaksi antara Narasumber dan jamaah. Komunikasi yang terjadi antara Narasumber dan jamaah adalah komunikasi dua arah, sehingga tidak membosankan.

Husein dalam penelitiannya mampu menemukan 7 karakteristik komunikasi yang terjadi pada pengajian Maiyah Mocopat Syafaat. 7 karakter tersebut di antaranya Komunikasi kultural, Komunikasi Egaliter, Komunikasi Interaksional, Komunikasi Kontekstual, Komunikasi Dekonstruktif, Komunikasi Analogis, dan Retorika Rekreatif ${ }^{18}$. Dari tujuh karakteristik komunikasi tersebut, konstruksi sosial Islam moderat lebih banyak dibangun dengan komunikasi Interaksional, komunikasi Egaliter dan komunikasi Analogis. Hal ini terlihat dari cara cak nun menjelaskan pengetahuan tertentu kepada para Jamaah Maiyah Mocopat Syafaat. Ia lebih banyak berkomunikasi dengan langsung berinteraksi kepada para jamaah dan disisipkan analogi-analogi tertentu untuk memberikan pemahaman kepada jamaah. Hal ini semakin menguatkan bahwa pembentukan lingkungan sebagai wujud eksternalisasi Islam moderat pada pengajian Jamaah Maiyah Mocopat Syafaat akan sangat memunculkan daya tarik bagi generasi milenial.

Pola pengajian selanjutnya yang membuat daya tarik generasi milenial untuk ikut pengajian ini yakni hiburan musik kyai kanjeng. Kyai kanjeng membawakan musik tidak hanya musik-musik

\footnotetext{
${ }^{17}$ Okta Budi Lestari, wawancara dengan Okta Budi Lestari pada tanggal 30 Juli 2019, July 30, 2019, 4.

18 Ahmad Sadam, "Karakteristik Komunikasi Emha Ainun Nadjib Dalam Penanaman Nilai-Nilai Pendidikan Islam Di Forum Maiyah Mocopat Syafaat.”
} 
KONSTRUKSI SOSIAL ISLAM ...

yang bernuansa Islam, seperti sholawatan atau lagu-lagu Qasidah saja, melainkan mereka juga membawakan lagu-lagu pop, barat yang sedang tren di kalangan generasi milenial. Hal tersebut didukung oleh komposisi musisi yang dimiliki oleh Kyai kanjeng juga tidak biasa. Mereka memiliki komposisi musik percampuran atau kolaborasi antara musisi tradisional dan modern. Selain itu, instrumen musik Kyai kanjeng merupakan campuran Gamelan dan instrumen musik barat seperti violin, bass elektrik dan keyboard ${ }^{19}$. Sehingga karakter musik yang dibawakan tidak biasa dan unik. Musik kyai kanjeng juga diterima oleh masyarakat luas. Bahkan musik kyai kanjeng juga menjadi fenomena tersendiri dalam sebuah kajian perkembangan musik di Indonesia.

Pengajian Jamaah Mocopat Syafaat ini merupakan pengajian tematik. Tema-tema pengajian yang diangkat biasanya di tentukan oleh Emha Ainun Najib (Cak Nun) atau sering juga ditentukan oleh tim penyelenggara yaitu Progres. Tema-tema pada pengajian ini tidak hanya sebatas tentang keagamaan, tetapi juga mengangkat tema-tema kehidupan pribadi dan sosial seorang muslim menyangkut cara hidup, hubungan dengan orang lain dan motivasi untuk hidup merdeka. Misalkan, pada pengajian tanggal 17 Juli 2019 lalu dimana peneliti hadir langsung dalam forum kajian tersebut. Pada forum itu pengajian Mocopat Syafaat mengangkat tema "Mendalami fadhilah dan otentitas diri menuju cerdas dunia dan akhirat". Pada tema tersebut point utama dalam kajian hari itu adalah mendorong kepada para jamaah untuk menjadi diri sendiri, tidak perlu menjadi orang lain. Menjadi diri yang otentik.

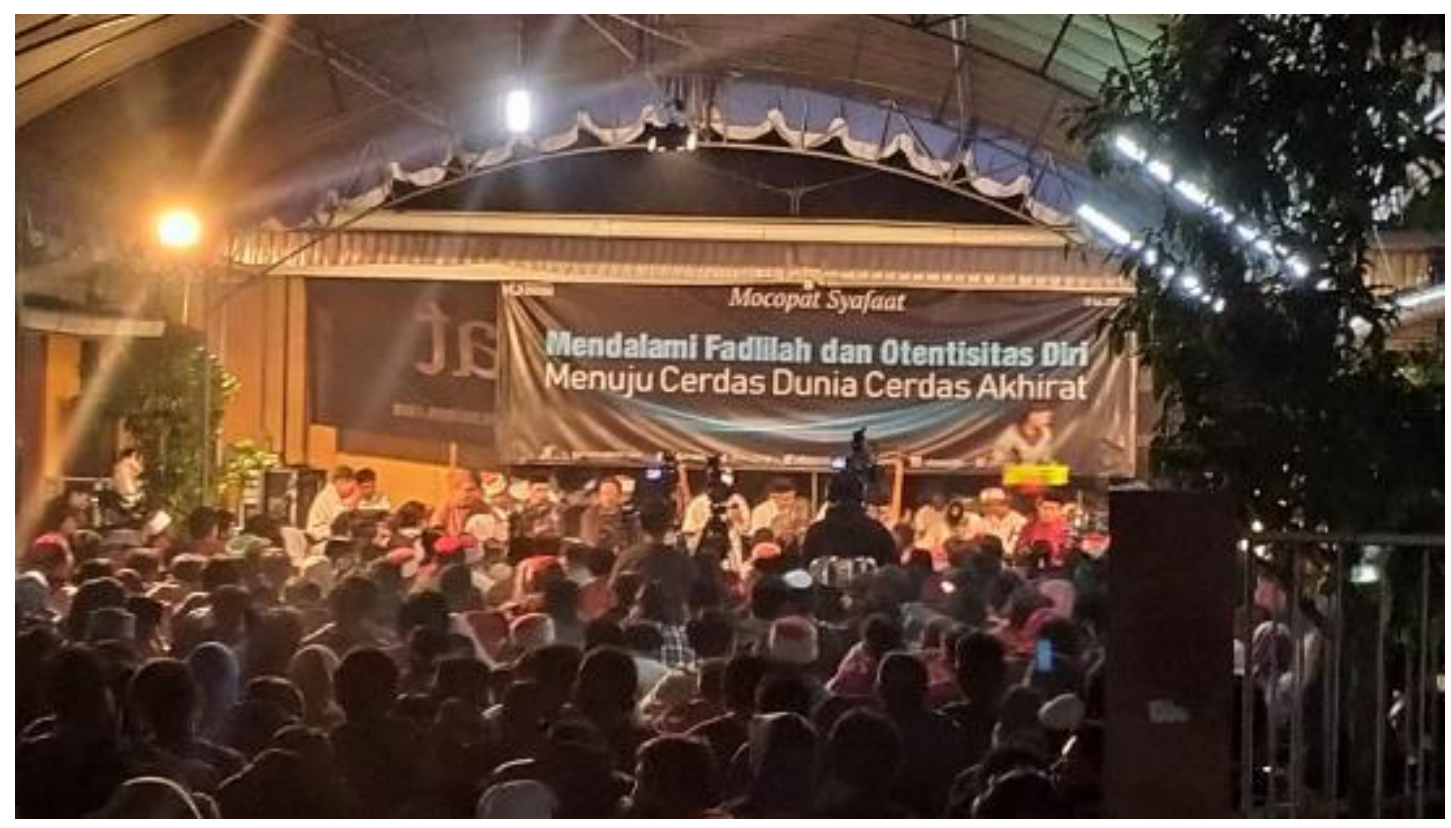

Sumber: Dokumen penelitian

Gambar 1. Pengajian mocopat syafaat dengan tema "Mendalami Fadhilah dan otentisitas diri menuju cerdas dunia cerdas Akhirat.

Dari gambar di atas dapat kita ketahui bahwa tema-tema yang diangkat pada forum tersebut tidak selalu tentang agama atau masalah fiqih misalnya. Tetapi topik forum tersebut berbicara masalah kehidupan dan motivasi hidup bagi generasi milenial. Bahwa seseorang itu harus memiliki ciri khas atau dalam kajian kala itu didefinisikan sebagai otentisitas diri. Dalam penjelasan cak nun dan narasumber lainnya menjelaskan bahwa boleh saja kita belajar dari negara atau bangsa lain,

${ }^{19}$ Franki S. Notosudirdjo, "Kyai Kanjeng: Islam and the Search for National Music in Indonesia," The World of Music 45, no. 2 (2003), hlm: 42. 
KONSTRUKSI SOSIAL ISLAM ...

namun jangan lupakan darimana kita berasal. Dan sejatinya itu adalah identitas diri kita. Selain itu, dari gambar di atas juga bisa dipahami bahwa tidak ada jarak antara jamaah dengan pembicara. Bahkan panggung pun tidak ada. Hal ini dijelaskan oleh salah satu panitia penyelenggara bahwa hal tersebut sebagai simbol tidak adanya sekat antara narasumber dan jamaah. Dan antara pembicara dan jamaah melebur menjadi satu. Tidak ada yang lebih tinggi antara satu dengan yang lain.

Tema yang diangkat dalam pengajian tentunya akan berdampak pada narasumber yang diundang. Narasumber pada pengajian ini juga tidak hanya Cak Nun saja, tetapi ada juga narasumber lain. Namun, Narasumber utamanya adalah Cak nun. Sosok cak nun adalah sosok yang sangat dinanti-nanti oleh jamaah maiyah ini, meskipun tidak seluruhnya cak nun berbicara dari awal hingga akhir. Narasumber lain selalu berganti-ganti di setiap pengajian. Kebutuhan narasumber ini menyesuaikan dengan tema yang diangkat. Narasumber pengajian yang selalu berganti sesuai dengan tema ini juga menarik perhatian para jamaah Maiyah Mocopat Syafaat ini. Bahkan pernah juga narasumber pengajian ini lintas agama.

Sosok cak nun dalam pengajian ini memiliki daya tarik sendiri bagi para jamaah Maiyah Mocopat Syafaat. Bahkan mereka yang hadir dalam pengajian ini pun tidak sedikit hanya ingin mendengarkan materi dari cak nun. Ada semacam kharisma yang dimiliki oleh cak nun sehingga ia dapat menjadi daya tarik pada pengajian ini. Menurut teori kepemimpinan karismatik, pemimpin memiliki kemampuan untuk menggerakkan orang lain dengan mendayagunakan keistimewaan atau kelebihan dalam sifat atau aspek kepribadian yang dimiliki pemimpin, sehingga menimbulkan rasa menghormati, segan dan kepatuhan ${ }^{20}$. Cak nun dapat dikategorikan ke dalam pemimpin kharismatik. Sehingga, menjadi daya Tarik tersendiri bagi Jamaah Mocopat Syafaat. Dalam pengajian tersebut, cak nun lebih memposisikan diri sebagai orang yang di tua kan. Hal ini dapat dilihat dari panggilan atau sapaan para jamaah kepada beliau yaitu dengan panggilan "mbah nun”. Mbah merupakan panggilan seorang cucu kepada kakek dalam tradisi masyarakat Jawa. Cak nun tidak mau dipanggil ustadz, kiai atau habib. Tetapi ia lebih nyaman di panggil dengan panggilan mbah. Panggilan tersebut mengisyaratkan tentang kecintaan cak nun kepada para jamaah. Panggilan tersebut juga memiliki pesan bahwa tidak ada jarak antara jamaah dan cak nun. Cak nun menganggap para jamaah yang didominasi oleh kaum milenial sebagai cucunya sendiri. Kedekatan ini juga yang menimbulkan rasa nyaman bagi para jamaah.

\section{Obyektivasi Islam moderat pada pengajian Maiyah Mocopat Syafaat terhadap generasi milenial}

Pada bagian sebelumnya telah dijelaskan tentang eksternalisasi Islam moderat oleh Mocopat Syafaat pada generasi milenial. Masyarakat adalah produk dari manusia, berakar pada fenomena eksternalisasi, yang pada gilirannya didasarkan pada konstruksi biologis manusia itu ${ }^{21}$. Eksternalisasi tersebut membentuk kenyataan subjektif dalam diri seseorang, terutama generasi milenial tentang Islam moderat. Sehingga setiap orang yang ikut pada pengajian tersebut membentuk sebuah kesadaran subjektif tentang Islam moderat, yang kemudian menjadi kepercayaan secara umum bagi pengikut jamaah Maiyah Mocopat Syafaat ini. kepercayaan secara umum ini kemudian menjadi sebuah kenyataan obyektif jamaah Maiyah Mocopat Syafaat tentang Islam moderat atau Islam yang ramah.

${ }^{20}$ Ferri Wicaksono, "Kiai Kharismatik Dan Hegemoninya (Telaah Fenomena Habib Syech Bin Abdul Qadir Assegaf)," Jurnal Pemerintahan Dan Politik 3, no. 3 (May 23, 2019), hlm: 124, https://doi.org/10.36982/jpg.v3i3.678.

${ }^{21}$ Berger, Langit Suci: Agama Sebagai Realitas Sosial, hlm: 11. 
KONSTRUKSI SOSIAL ISLAM ...

Islam moderat dipahami sebagai Islam yang ramah, Islam yang damai dan Islam anti kekerasan serta mampu menghargai orang lain. Hal tersebut sudah menjadi kenyataan subjektif bagi jamaah Maiyah Mocoopat Syafaat. Selain itu, pengajian Mocopat Syafaat ini juga mampu menanamkan sikap yang mampu menerima dan menghargai perbedaan kepada jamaahnya. Jamaah Mocopat Syafaat sangat tidak sepakat dengan kekerasan apa pun bentuknya, apa lagi kekerasan yang mengatas namakan agama. Dengan dalih menolong agama, maka masyarakat atau oknum penganut agama tertentu rela melakukan tindakkan kekerasan. Perbedaan yang menimbulkan kekerasan itu terjadi karena banyaknya tafsir-tafsir atas agama.

Kerusuhan dan kekerasan yang terjadi pada kehidupan sosial membuat kehidupan tidak nyaman. Sehingga siapapun dia pasti akan menolak kekerasan dalam bentuk apa pun dan atas nama apa pun. Dari beberapa pernyataan di atas, kita dapat mengetahui bahwa, Eksternalisasi generasi milenial pada jamaah Maiyah Mocopat Syafaat melahirkan pribadi-pribadi yang moderat. Jamaah Maiyah Mocopat Syafaat adalah aktivitas manusia yang diobyektifkan, suatu aktivitas manusia yang telah memperoleh status realitas obyektif.

Pengalaman peneliti terlibat langsung dalam pengajian mocopat syafaat ini menguatkan penjelasan responden di atas. Memang forum-forum yang di adakan oleh MMS salh satunya menanamkan sikap toleransi dan menghargai sesama. Sehingga para jamaah forum MMS ini tidak mudah tersulut dengan konflik-konflik yang terjadi di Indonesia. Mereka tidak mudah terprovokasi oleh informasi-informasi yang dapat menimbulkan konflik. Hal tersebut juga terlihat pada aktivitas sosial media jamaah MMS ini. Sikap toleran dan menghargai kemanusiaan selalu diselipkan di setiap forum kajian ini.

\section{Internalisasi Islam moderat pada jamaah Maiyah Mocopat Syafaat}

Individu tidak dicipta sebagai suatu benda yang pasif dan lebam (diam), sebaliknya, dia dibentuk selama suatu dialog yang lama (menurut pengertian yang literal adalah suatu dialektik) yang di dalamnya dia sebagai seorang peserta. Yaitu dunia sosial ${ }^{22}$. Dunia obyektivasi-obyektivasi sosial itu, yang dihasilkan melalui pengeksternalisasian kesadaran, menghadapi kesadaran sebagai suatu faktisitas eksternal. Internalisasi adalah penyerapan ke dalam kesadaran dunia yang terobyektivasikan sedemikian rupa sehingga struktur dunia ini menentukan struktur subyektif. Kesadaran itu sendiri yaitu, masyarakat kini berfungsi sebagai pelaku formatif bagi kesadaran individu. Sejauh internalisasi itu telah terjadi, individu kini memahami berbagai unsur dunia yang terobyektivasi sebagai fenomena yang internal terhadap kesadarannya bersamaan dengan saat dia memahami unsur-unsur itu sebagai fenomena realitas eksternal ${ }^{23}$.

Setiap masyarakat yang terus berjalan dalam sejarah akan menghadapi pengalihan maknamakna terobyektivasinya dari satu generasi ke generasi berikutnya. Pemahaman Islam moderat pada generasi milenial sebagai hasil dari eksternalisasi dan obyektivasi dari pengajian jamaah maiyah dapat saja luntur dan beralih kepada makna-makna yang lain. Ini adalahlah sebuah masalah, karena akan terjadi perubahan makna-makna. Masalah ini terselesaikan dengan cara proses sosialisasi. Sosialisasi merupakan proses yang dipakai mendidik generasi baru untuk hidup sesuai dengan program-program kelembagaan masyarakat tertentu ${ }^{24}$. Sosialisasi Islam moderat pada generasi milenial terbagi menjadi dua hal, yaitu sosialisasi primer dan sosialisasi sekunder. Pada bagian ini

\footnotetext{
${ }^{22}$ Berger, Langit Suci: Agama Sebagai Realitas Sosial, hlm:23.

${ }^{23}$ Berger, hlm: 19.

${ }^{24}$ Berger, hlm: 19.
} 
KONSTRUKSI SOSIAL ISLAM ...

akan dideskripsikan internalisasi Islam moderat pada generasi milenial baik pada sosialisasi primer maupun pada sosialisasi sekunder

\section{Sosialisasi primer Islam moderat pada generasi milenial}

Sosialisasi primer sebagai fase internalisasi pertama pada kehidupan manusia pada sebuah kenyataan memiliki peranan yang sangat penting bagi seseorang. Sosialisasi primer adalah sosialisasi pertama yang dialami individu pada masa kanak-kanak, sehingga dari proses itu anakanak menjadi anggota masyarakat ${ }^{25}$. Pada fase ini individu mengenal Islam yang ramah, Islam damai atau Islam moderat dari orang-orang yang berpengaruh dengan kenyataan objektif yang akan diinternalisasikan pada sang anak. Berger meyakini bahwa semua pengalaman keagamaan berlangsung dalam suatu konteks sosial, bahkan pada diri seorang pertama yang membawa serta dengannya konteks sosial yang telah diinternalisasikan ${ }^{26}$. Sosialisasi primer Islam moderat pada generasi milenial dimulai dari keluarga. Lingkungan keluarga sebagai tempat sosialisasi primer yang mengajarkan Islam damai, dan tidak pernah mengajarkan fanatik. Fanatisme agama yang berlebihan sangat berbahaya bagi kehidupan orang lain. Sangat bertolak belakang dengan diutusnya agama itu sendiri bagi kehidupan manusia. Di mana agama ada karena untuk menjadikan kehidupan umat manusia yang damai, sejahtera dan aman. Ketika fanatisme agama ada pada diri seseorang, maka akan memicu tindakan radikal. Dalam beberapa kasus, fanatisme agama menyebabkan orang dapat dengan mudah melakukan kekerasan demi "agenda suci" mereka sebagaimana mereka pahami ${ }^{27}$. Bahkan KH. Ma'ruf amin, mensinyalir bahwa fanatisme yang berlebihan menyebabkan tumbuh suburnya radikalisme di negeri ini. ketika terjadi perbedaan pendapat akan dianggap sebagai musuhnya. Bahkan tak hanya orang yang berbeda agama, yang seagama pun bila berbeda pendapat akan tetap dianggap sebagai lawan ${ }^{28}$. Oleh karena itu, lingkungan keluarga yang mengajarkan fanatisme secara berlebihan akan melahirkan anak-anak yang dengan mudah melakukan kekerasan.

Orang tua, terutama bapak sebagai kepala keluarga dan ibu sebagai kepala rumah tangga, merupakan aktor-aktor utama dalam mewarnai proses pembinaan, pendidikan, pertumbuhan dan perkembangan kepribadian anak-anak. Kepribadian ideal anak-anak sangat bergantung kepada upaya yang dilakukan kedua orang tua sedini mungkin hingga anak-anak mampu memahami berbagai pengenalan, pengalaman sosial baik melalui bimbingan, latihan-latihan dan pendidikan, terutama melalui proses pembinaan keagamaan dengan baik ${ }^{29}$. Internalisasi Islam moderat pada lingkungan keluarga menjadi dasar bagi generasi milenial dalam menjalankan kehidupannya di lingkungan masyarakat. Keluarga harus sudah memberikan pemahamanpemahaman tentang Islam yang damai, Islam yang menyejukkan kepada anak, agar ketika ia beraktivitas bergaul pada lingkungan luar (selain keluarga) tidak kembali terobyektivasi dengan paham-paham puritan atau paham keras.

25 Peter L. Berger and Thomas Luckmann, Tafsir Sosial Atas Kenyataan: Risalah Tentang Sosiologi Pengetahuan. (Jakarta: LP3S, 2013), hlm: 178.

${ }^{26}$ Peter L. Berger and Hansfried Keller, Sosiologi Ditafsirkan Kembali: Esai Tentang Metode Dan Bidang Kerja. (Jakarta: LP3S, 1985), hlm: 98.

${ }_{27}$ Ali Muhtarom et al., Islam Agama Cinta Damai: Upaya Menepis Radikalisme Beragama. (Semarang: Pilar Nusantara, 2018), hlm: 19.

${ }^{28}$ Muhtarom et al., hlm: 20.

29 Syafi'ah Sukaimi, "Peran Orang Tua Dalam Pembentukan Kepribadian Anak: Tinjauan Psikologi Perkembangan Islam," Marwah: Jurnal Perempuan, Agama Dan Jender 12, no. 1 (June 2, 2013), hlm: 81-90, https://doi.org/10.24014/marwah.v12i1.515. 
KONSTRUKSI SOSIAL ISLAM ...

Orang tua adalah orang yang paling berpengaruh terhadap anak atau individu. Ia juga adalah orang yang paling dipercayai oleh anak. Ketika keluarga tidak mampu menjawab pertanyaanpertanyaan anak terkait Islam, maka sang anak akan mencari jawaban tersebut di luar lingkungan keluarganya. Hal ini yang kemudian dapat menjadi peluang bagi sang anak untuk terpengaruh paham-paham puritan.

Masa adalah masa di mana seorang remaja ada pada posisi keadaan psikis yang labil. Ia mudah terpengaruh oleh pemikiran atau bahkan tindakan dari luar dirinya yang seolah-olah benar, namun sejatinya salah. Peran orang tua dalam lingkungan keluarga di sinilah sangat besar. Keluarga harus menjadi rujukan utama bagi sang anak. Ayah atau ibu harus menjadi orang yang utama bagi anak untuk memenuhi segala kebutuhan. Tidak hanya kebutuhan fisik sang anak, kebutuhan pengetahuan, kebutuhan psikis dan mental juga harus keluarga atau orang tua penuhi. Demi masa depan anak yang lebih baik lagi.

Berger menjelaskan bahwa, pada sosialisasi primer, tidak hanya melibatkan pada aspek kognitif tetapi juga kondisi-kondisi yang bermuatan emosi yang tinggi. Tanpa hubungan emosional yang kuat dari orang yang berpengaruh, maka proses belajar akan sulit ${ }^{30}$. Breger seolah memberi isyarat bahwa orang yang paling berpengaruh dalam membangun pemahaman Islam moderat adalah orang tua atau lingkungan keluarga dibandingkan orang lain.

Menurut Berger, dalam sosialisasi primer tidak ada masalah identifikasi. Orang-orang yang berpengaruh tidak dapat dipilih. Masyarakat menyediakan sekelompok orang-orang berpengaruh tertentu bagi sosialisasi seorang anak, yang harus ia terima sebagaimana adanya tanpa kemungkinan untuk memilih sekelompok yang lain ${ }^{31}$.

\section{Sosialisasi sekunder Islam moderat pada generasi milenial}

Kehidupan individu tidak terbatas pada lingkungan keluarga saja. Namun ia akan tetap membutuhkan orang lain untuk melangsungkan hidupnya. Kehidupan selain lingkungan keluarga ini yang disebut Berger juga berperan dalam internalisasi. Internalisasi pada fase ini disebut dengan sosialisasi sekunder. Sosialisasi sekunder adalah proses memperoleh pengetahuan khusus sesuai dengan peranannya (role specific knowledge), di mana peranan-peranan secara langsung atau tidak langsung berakar dalam pembagian kerja. Sosialisasi sekunder adalah internalisasi sejumlah "sub dunia" kelembagaan atau berlandaskan lembaga. Sub dunia-sub dunia yang diinternalisasikan dalam sosialisasi sekunder pada umumnya merupakan kenyataan-kenyataan parsial, berbeda dengan “dunia dasar" yang diperoleh dalam sosialisasi primer ${ }^{32}$.

Islam moderat atau Islam ramah tidak hanya diajarkan oleh keluarga saja. Bahkan mungkin ada juga individu yang tidak mendapati ajaran Islam yang ramah di lingkungan keluarganya, justru malah di lingkungan keduanya pada fase sosialisasi sekunder ini. Pengajian Mocopat Syafaat ini menjadi lembaga tempat sosialisasi sekunder pemahaman Islam moderat bagi generasi milenial. Walaupun sebenarnya pendidikan agama bukan hanya diajarkan di pengajian ini. tetapi di lembagalembaga pendidikan formal mereka menerima pendidikan agama.

Pandangan Islam moderat, Islam yang damai seperti inilah yang diharapkan ada pada setiap generasi milenial. Sosialisasi sekunder yang didapat oleh generasi milenial saat ini tidak hanya sebatas dari pengajian mocopat syafaat, tetapi ia juga bisa mendapatkan dari media sosial seperti youtube, atau bacaan buku.

\footnotetext{
${ }^{30}$ Berger and Luckmann, Tafsir Sosial Atas Kenyataan: Risalah Tentang Sosiologi Pengetahuan., hlm: 179-80.

${ }^{31}$ Berger and Luckmann, hlm: 183.

${ }^{32}$ Berger and Luckmann, hlm: 189.
} 
KONSTRUKSI SOSIAL ISLAM ...

Berger menjelaskan bahwa sosialisasi primer tidak dapat berlangsung tanpa suatu identifikasi yang bermuatan emosional di pihak lain anak dengan para pengasuhnya, kebanyakan sosialisasi sekunder tidak memerlukan identifikasi semacam itu, dan bisa berlangsung secara efektif dengan hanya identifikasi timbal balik sebanyak yang masuk dalam tiap komunikasi antar manusia. Secara sederhana dapat dikatakan bahwa orang perlu mencintai ibunya tetapi tidak gurunya ${ }^{33}$. Sosialisasi sekunder Islam moderat dapat dilakukan oleh siapa saja. Tidak seperti sosialisasi primer yang terjadi di lingkungan keluarga dan tergantung kepada hubungan emosional antara anak dan ayah atau ibu. Sehingga pemahaman Islam apakah ia moderat ataupun puritan sebenarnya dilakukan oleh siapa saja. Karena dalam sosialisasi primer, si anak tidak memahami orang lain yang berpengaruh sebagai fungsionaris-fungsionaris kelembagaan, tetapi sebagai semata-mata perantara bagi kenyataan.

Warna kenyataan dari pengetahuan yang diinternalisasikan dalam sosialisasi primer merupakan hal yang timbul secara kuasi otomatis. Dalam sosialisasi sekunder dia harus diperkuat dengan teknik-teknik khusus pedagogis, yang "dibawa ke rumah" si individu. Teknik-teknik pedagogis tersebut yang banyak sekali ditemukan di pengajian Maiyah Mocopat Syafaat. Misalkan saja, cara cak nun menjawab beberapa pertanyaan dan diskusi dari jamaah atau peserta. PNY menjelaskan bahwa teknik yang digunakan oleh Maiyah Mocopat Syafaat untuk menanamkan Islam moderat kepada para jamaah generasi milenial adalah dengan berdialog langsung kepada para jamaah. Sesi dialog pasti ada dalam setiap pengajian. Model dialog yang dilakukan oleh Cak nun biasanya yaitu dengan meruntuhkan terlebih dahulu pemahaman yang kurang tepat dari jamaahnya, kemudian membangun kembali dengan pemahaman Islam moderat yang baik. Selain dialog, cak nun sebagai narasumber utama dalam pengajian tersebut juga selalu menggunakan analogi-analogi sederhana, sehingga jamaah dapat memahami apa yang dimaksudkan oleh narasumber.

\section{Kesimpulan dan Saran}

Berdasarkan temuan dalam artikel ini dapat disimpulkan bahwa konstruksi sosial islam moderat jamaah maiyah mocopat syafaat terhadap generasi milenial terjadi dalam 3 tahapan yaitu, Eksternalisasi, objektivasi dan internalisasi. Kegiatan yang berlangsung selama pengajian Mocopat Syafaat ini diantaranya tadarus Al-Quran, Shalawat, Diskusi kelompok, penyampaian materi dari Narasumber, sharing, dan acara disisipi penampilan musik Kyai kanjeng. Proses eksternalisasi berhasil melahirkan pemahaman Islam moderat, Islam ramah dan Damai kepada generasi milenial pada pengajian Mocopat Syafaat. Pemahaman tersebut telah menjadi kenyataan obyektif bagi generasi milenial. Yang sekaligus menjadi kontra atas pemahaman Islam puritan bahkan radikal. Generasi milenial telah sadar menolak kekerasan dan fanatisme berlebihan terhadap agama.Proses internalisasi Islam moderat pada generasi milenial meliputi sosialisasi primer dan sosialisasi sekunder. Sosialisasi primer dilakukan pada lingkungan keluarga. Dalam hal ini ayah atau ibu adalah orang yang paling berpengaruh terhadap pemahaman Islam yang ramah, Islam yang damai, Islam moderat. Sedangkan sosialisasi sekunder terjadi di lembaga-lembaga pendidikan seperti sekolah, pengajian di lingkungan sekitar tempat tinggal, termasuk di dalam pengajian jamaah mocopat syafaat.

Bagi penyelenggara pengajian Mocopat Syafaat disarankan memperlebar atau memperdalam materi-materi terkait dengan masalah-masalah Syariah dan Fiqh. Hal demikian akan semakin memperkuat sikap moderasi beragama para jamaah Maiyah Mocopat syafaat. Sebab perbedaan

\footnotetext{
${ }^{33}$ Berger and Luckmann, Tafsir Sosial Atas Kenyataan: Risalah Tentang Sosiologi Pengetahuan., hlm: 192.
} 
KONSTRUKSI SOSIAL ISLAM ...

permasalahan fiqh ini terkadang menjadi akar konflik di tengah masyarakat Indonesia Bagi penelitian selanjutnya, Maiyah Mocopat syafaat juga dapat dikaji dari sudut pandang manajemen Pendidikan, terutama terkait dengan Hidden kurikulum yang ada pada kajian tersebut, atau juga dari sudut pandang ekonomi dan kesejahteraan umat.

\section{E. Daftar Pustaka}

Ahmad Sadam, Husaein. "Karakteristik Komunikasi Emha Ainun Nadjib Dalam Penanaman NilaiNilai Pendidikan Islam Di Forum Maiyah Mocopat Syafaat.” Thesis, Universitas Islam Negeri Yogyakarta, 2015.

Berger, Peter L. Langit Suci: Agama Sebagai Realitas Sosial. Jakarta: LP3S, 1991.

Berger, Peter L., and Hansfried Keller. Sosiologi Ditafsirkan Kembali: Esai Tentang Metode Dan Bidang Kerja. Jakarta: LP3S, 1985.

Berger, Peter L., and Thomas Luckmann. Tafsir Sosial Atas Kenyataan: Risalah Tentang Sosiologi Pengetahuan. Jakarta: LP3S, 2013.

. The Social Construction of Reality: A Treatise in the Sociology of Knowledge. Great Britain: Penguin Books Ltd, 1991.

Creswell, John W. Qualitative Inquiry and Research Design: Choosing among Five Approach. 2nd ed. London: SAGE Publication, 2017.

Hakim, Ramlah. "Paham dan sikap keagamaan mahasiswa muslim di kota Samarinda." Al-Qalam 16, no. 1 (August 12, 2018): 17-24. https://doi.org/10.31969/alq.v16i1.490.

Lestari, Okta Budi. wawancara dengan Okta Budi Lestari pada tanggal 30 Juli 2019.

Misrawi, Zuhairi. Pandangan Muslim Moderat: Toleransi, Terorisme Dan Oase Perdamaian. Jakarta: KOMPAS, 2010.

M.N, Huda. Pemuda, Kelas Menengah Muslim, Dan Tantangan Intoleransi Dan Radikalisme Di Perkotaan. Jakarta: Wahid Foundation, 2017.

Muhtarom, Ali, Abdul Karim, Achmad Choiron, Jamal Ma'mur Asmani, and Yusuf Hasyim. Islam Agama Cinta Damai: Upaya Menepis Radikalisme Beragama. Semarang: Pilar Nusantara, 2018 .

Munip, Abdul. "Menangkal Radikalisme Agama Di Sekolah.” Jurnal Pendidikan Islam 1, no. 2 (December 25, 2012): 159-81. https://doi.org/10.14421/jpi.2012.12.159-181.

Mustafa, Muhammad Azizul. "Maiyah mocopat syafaat dalam perspektif psikologi." LENTERA 1, no. 01 (June 18, 2017). https://doi.org/10.21093/lentera.v1i01.839.

Notosudirdjo, Franki S. "Kyai Kanjeng: Islam and the Search for National Music in Indonesia." The World of Music 45, no. 2 (2003): 39-52.

Prayogi R., Saputra. Spiritual Journey: Pemikiran Dan Perenungan Emha Ainun Nadjib. Jakarta: KOMPAS, 2012.

Sukaimi, Syafi'ah. "Peran Orang Tua Dalam Pembentukan Kepribadian Anak: Tinjauan Psikologi Perkembangan Islam.” Marwah: Jurnal Perempuan, Agama Dan Jender 12, no. 1 (June 2, 2013): 81-90. https://doi.org/10.24014/marwah.v12i1.515.

Umar, Ahmad Rizky Mardhatillah. "Melacak Akar Radikalisme Islam Di Indonesia.” Jurnal Ilmu Sosial Dan Ilmu Politik 14, no. 2 (November 1, 2010): 169-86. https://doi.org/10.22146/jsp.10935.

Wicaksono, Ferri. "Kiai Kharismatik Dan Hegemoninya (Telaah Fenomena Habib Syech Bin Abdul Qadir Assegaf)." Jurnal Pemerintahan Dan Politik 3, no. 3 (May 23, 2019). https://doi.org/10.36982/jpg.v3i3.678. 